Research Paper

\title{
The effects of storage time and temperature on the stability of salivary phosphatases, transaminases and dehydrogenase
}

\author{
Damaris Raissa dos Santos ${ }^{\mathrm{a}, \mathrm{b}, 1}$, Rayne Oliveira Souza ${ }^{\mathrm{a}, \mathrm{b}, 1}$, Layani Bertaglia Dias ${ }^{\mathrm{b}}$, \\ Tayná Buffulin Ribas ${ }^{\mathrm{b}}$, Luis Cezar Farias de Oliveira ${ }^{\mathrm{a}}$, Doris Hissako Sumida ${ }^{\mathrm{b}, \mathrm{c}}$, \\ Rita Cássia Menegati Dornelles ${ }^{\mathrm{b}, \mathrm{c}}$, Ana Cláudia de Melo Stevanato Nakamune ${ }^{\mathrm{b}, \mathrm{c}}$, \\ Antonio Hernandes Chaves-Neto ${ }^{\text {b,c, }}$ \\ a Paulista University (UNIP), Araçatuba, Avenida Baguaçu, 1939, CEP 16018-555, São Paulo, Brazil \\ b Department of Basic Sciences, São Paulo State University (Unesp), School of Dentistry, Araçatuba, Rodovia Marechal Rondon 527/528 km, Campus Universitário, CEP \\ 16018-805, São Paulo, Brazil \\ c Programa Multicêntrico de Pós-Graduação em Ciências Fisiológicas - SBFis, São Paulo State University (Unesp), School of Dentistry, Rodovia Marechal Rondon 527/ \\ 528 km, Campus Universitário, CEP 16018-805, São Paulo, Brazil
}

\section{A R T I C L E I N F O}

\section{Keywords:}

Saliva

Phosphatases

Transaminases

Dehydrogenase

Storage

Temperature

\begin{abstract}
A B S T R A C T
Objectives: To investigate the influence of temperature and storage time on salivary acid phosphatase (ACP), tartrate-resistant acid phosphatase (TRAP), alkaline phosphatase (ALP), aspartate aminotransferase (AST) and alanine aminotransferase (ALT) and lactate dehydrogenase (LDH).

Design: Unstimulated whole expectorated saliva was collected from healthy men and women subjects $(n=26)$ between 8 and 10 a.m. The saliva samples were centrifuged, and the supernatants were measured for ACP, TRAP, ALP, AST, ALT and LDH activities immediately (without freezing) [baseline values] and after time intervals of 3 , 7, 14 and 28 days (d) of storage at $-20{ }^{\circ} \mathrm{C}$ and $-80{ }^{\circ} \mathrm{C}$ using spectrophotometric methods The influence of storage time was analyzed by one-way ANOVA followed by the Dunnett post-test, while the paired Student's-ttest was used to compare the differences between the temperature $(p<0.05)$.

Results: There was significant decline in the activities of all enzymes at $-20{ }^{\circ} \mathrm{C}$ with increasing storage time. This decrease was relevant from day 14 onward for the majority of the enzymes, with the exception of AST. After day 28, the more sensitive enzymes were ALP and LDH, which showed residual activity of $39 \%$ and $16 \%$, respectively, compared with baseline values. There were considerable, but insignificant changes, in the activities of all enzymes after storage at $-80^{\circ} \mathrm{C}$ for 28 days.

Conclusions: Frozen samples should be kept at $-80{ }^{\circ} \mathrm{C}$ to preserve these activities, but there are restrictions for the enzymes ALP, ALT and LDH. Storage of samples at $-20^{\circ} \mathrm{C}$ could introduce high error variance in measured activities.
\end{abstract}

\section{Introduction}

Total saliva is composed of water, electrolytes, proteins, enzymes, volatile compounds, hormones of endogenous origin and cellular components such as desquamated epithelial mucosa and microorganisms (Al Kawas, Rahim, \& Ferguson, 2012; Naumova et al., 2012). Saliva is involved in the processes of lubrication, digestion, neutralization of acids and bases, protection against demineralization, and has antimicrobial function (Pannunzio et al., 2010). Saliva is considered a diagnostic tool capable of providing molecular biomarkers for prevention, monitoring and diagnosis of various oral and systemic diseases and conditions, such as caries, periodontitis, oral cancer, diseases of the salivary glands and systemic disorders such as hepatitis and HIV. The advantages of using saliva as a diagnostic fluid are easy collection; noninvasive, low cost-effectiveness, and prompt availability (Nagler, Hershkovich, Lischinsky, Diamond, \& Reznick, 2002). However, the success of analyte measurement requires optimal conditions and procedures for collection, processing and storage (Henson \& Wong, 2010), because many factors may influence the stability of the analyte and accuracy of the test.

\footnotetext{
* Corresponding author at: Department of Basic Sciences, São Paulo State University (Unesp), School of Dentistry, Araçatuba, Rodovia Marechal Rondon, km 527, CEP 16018-805, Araçatuba, SP, Brazil.

E-mail address: antoniohernandes@foa.unesp.br (A.H. Chaves-Neto).

${ }^{1}$ These authors contributed equally to this work.
} 
Storage time and temperature, and oral health condition are some of the factors that may influence the stability of saliva components, thus being sources of errors in laboratory determinations. Storage and temperature are factors that influence steroid hormone concentrations because of their degradation by the action of salivary enzymes and the decomposing action of oral microorganisms (Kaufmann et al., 1999). A large range of errors in the measurement of testosterone and estradiol occur when saliva is stored at temperatures above $-20{ }^{\circ} \mathrm{C}$ (Toone et al., 2013). In contrast, cortisol concentration is stable for up to 3 months when stored at $5{ }^{\circ} \mathrm{C},-20^{\circ} \mathrm{C}$ and $-80^{\circ} \mathrm{C}$ (Garde \& Hansen, 2005). In turn, the concentration of Immunoglobulin A - Secretory (IgA-S) in saliva decreased as a function of storage time, while degradation was more accentuated at lower temperatures (Presser, Simuyandi, \& Brown, 2014). On the other hand, lysozyme concentrations have been shown to be stable for up to 3 months when stored at $-30{ }^{\circ} \mathrm{C}(\mathrm{Ng}$, Koh, Fu, \& Chia, 2003). The patient's oral health condition also influences the stability of analytes; for example, storing saliva from patients with periodontal disease is not recommended when malonaldehyde and total protein levels are measured (Emekli-Alturfan et al., 2013).

The influence of storage time and temperature on most salivary components, even those with importance for diagnosis and monitoring of systemic and local changes, remain unknown. Example are Acid phosphatase (ACP, EC 3.1.3.2), tartrate-resistant acid phosphatase (TRAP; EC EC 3.1.3.2), alkaline phosphatase (ALP, EC 3.1.3.1), lactate dehydrogenase (LDH, EC 1.1.1.27), aspartate aminotransferase (AST, EC 2.6.1.1) and alanine aminotransferase (ALT, EC 2.6.1.2), enzymes found in saliva and that are outstanding for their importance in the diagnosis and monitoring of oral and systemic diseases. The activity of the phosphatases has been evaluated in the saliva of diabetic patients (López et al., 2003), smokers (Prakash et al., 2016), cystic fibrosis (Oglesbee et al., 1984), post-menopausal women (Sophia, Suresh, Sudhakar, Jayakumar, \& Mathew, 2017) and healthy children (ChavesNeto, Sassaki, \& Nakmune, 2011). The increased activity of these enzymes in saliva has also been associated with the consequence of the destructive process of the alveolar bone and the degradation of tissues of in the advanced stage of periodontal disease (Dabra, China, \& Kaushik, 2012; Dabra \& Singh, 2012; Kaufman \& Lamster, 2000; Yoshie et al., 2007).

ALT, AST and LDH are markers of cellular damage and inflammation. There is evidence of the association between the salivary levels of these enzymes and periodontitis (Alptekin, Kurtoglu, Serpek, Duran, \& Gözlü, 2000; Cesco, Ito, \& de Albuquerque, 2003; Dabra et al., 2012; Fiorellini, Nevins, Sekler, Chung, \& Oringer, 2000; Kugahara, Shosenji, \& Ohashi, 2008; Totan, Greabu, Totan, \& Spinu, 2006), while the activity of ALT, AST and LDH tends to decrease in saliva after nonsurgical treatment of periodontitis (Yoshie et al., 2007). Higher levels of salivary LDH, AST, and ALT were attributed to autoimmunological damage associated with the pathophysiology of diabetes mellitus (Malicka, Skoskiewicz-Malinowska, \& Kaczmarek, 2016) and are therefore considered for monitoring the diabetic involvement of salivary glands (Musumeci et al., 1993; Verma et al., 2014). Furthermore, higher levels of salivary AST, and ALT may help with the early diagnosis of peptic ulcer (Boghori, Aghamaali, Sariri, Mohamadpour, \& Ghafouri, 2014).

Considering the need to store saliva samples correctly, to avoid compromising the accuracy of the laboratory determinations, this study was proposed. We hypothesized that temperature and time of storage may affect the stability of ACP, TRAP, ALP, ALT, AST and LDH. To evaluate these factors, we investigated the activity of these salivary enzymes, after storage at $-20^{\circ} \mathrm{C}$ and up to $-80^{\circ} \mathrm{C}$ immediately after collection, and after time intervals of $3,7,14$ and 28 days of storage.

\section{Materials and methods}

\subsection{Participants}

Saliva samples were obtained from healthy adult men $(\mathrm{n}=14)$ and women $(n=12)$ volunteers aged $18-36$ years. The research protocol was approved by the Human Ethics Committee on Research with Human Beings of the School of Dentistry, Araçatuba, São Paulo State University - UNESP (Permission Number CAAE 44627915.0.0000.5420 and 50712215.3.0000.5420). None of the volunteers had a history of chronic somatic illnesses such as autoimmune disease; diabetes; cancer; metabolic disturbances, or obesity; no history of neurological or psychiatric disorders; or alcohol abuse; and all of them were drug- free. In addition, participants had to be free of fever and/or cold; non-smokers; and have good oral hygiene, while participants with gingival and periodontal inflammation were excluded. To minimize any contamination of samples and to obtain a relatively constant baseline, participants were asked to refrain from brushing their teeth and eating or drinking in the 60 min prior to sample collection.

\subsection{Collection, processing and storage of saliva samples}

Unstimulated whole expectorated saliva $(5 \mathrm{ml})$ was collected from each subject between 8 and 10 a.m., considering the circadian rhythm, according to a modification in the method described by Navazesh (1993). Subjects rinsed their mouth with water $10 \mathrm{~min}$ prior to sampling. The first expectoration was discarded to eliminate food debris and unwanted substances capable of contaminating the saliva, which might have caused analytical inaccuracy. The saliva samples were then expectorated into sterile tubes kept on ice, while the subject was seated in an upright position. The samples were kept on ice to minimize degradation of salivary proteins until further processing. Immediately after saliva collection, $\mathrm{pH}$ and buffer capacity were determined using a portable $\mathrm{pH}$-meter. The buffer capacity was measured by titration using $1 \mathrm{ml}$ saliva, adding $0.2 \mathrm{ml}$ of $0.01 \mathrm{~mol} / \mathrm{L} \mathrm{HCl}$. The process of adding $0.2 \mathrm{ml}$ of $0.01 \mathrm{~N} \mathrm{HCl}$ was repeated, and $\mathrm{pH}$ was recorded until a $\mathrm{pH}$ level of 4.0 or less was reached (Bassoukou, Nicolau, \& dos Santos, 2009). To estimate the unstimulated whole saliva flow rate, saliva density was assumed to be $1 \mathrm{~g} / \mathrm{ml}$ as suggested by Flink, Tegelberg, and Lagerlöf (2005). Salivary flow rate was calculated by dividing the sample volume $(\mathrm{ml})$ by the time $(\mathrm{min})$ taken to produce it. The unstimulated whole saliva samples were centrifuged $\left(10,000 \times g\right.$ at $4{ }^{\circ} \mathrm{C}$ for $10 \mathrm{~min}$ ) to remove cellular debris and to minimize the turbidity of saliva, which could negatively impact on the accuracy of analysis (Schipper, Silletti, \& Vingerhoeds, 2007). The supernatant from each volunteer was divided into nine aliquots. The biochemical parameters of one aliquot were analyzed immediately after centrifugation (without freezing) [baseline values]. The remaining aliquots from each volunteer were stably stored at $-20^{\circ} \mathrm{C}$ (standard freezer) and $-80{ }^{\circ} \mathrm{C}$ (ultra-low temperature freezer), $\mathrm{n}=4$ aliquots for each temperature, until their analyses after time intervals of 3, 7, 14 and 28 days of storage. Aliquots were thawed once when needed and then discarded; refreezing was not allowed.

\subsection{Biochemical analysis of saliva}

The salivary total protein concentrations were determined by using the modified Lowry method by Hartree (1972) and was expressed as $\mathrm{mg} / \mathrm{L}$. TAP activity was measured by the method based on hydrolyses of the substrate $p$-nitrophenyl-phosphate ( $p N P P)$ to $p$-nitrophenol $(p N P)$ at $\mathrm{pH}$ 5.0, which has an intense yellow color at an alkaline $\mathrm{pH}$ (Granjeiro, Taga, \& Aoyama, 1997). TRAP activity was measured by hydrolyses of $p N P P$ to $p N P$ at $\mathrm{pH} 5.8$, in the presence of sodium tartarate and $p$-hydroxy mercury benzoate (Granjeiro et al., 1997; Janckila et al., 2005), the latter acts by inhibiting the low molecular weight acid phosphatases (Laidler, Taga, \& Van Etten, 1982). The TALP activity was measured 
based on the ability of these enzymes to catalyze the hydrolysis of $p$ NPP to $p \mathrm{NP}$ at $\mathrm{pH} 9.4$, in the presence of magnesium chloride (Chaves-Neto et al., 2011). In both determinations, the formation of $p N P$ was determined spectrophotometrically by means of reading the absorbance at $405 \mathrm{~nm}$, using a molar extinction coefficient of $18,000 \mathrm{M}^{-1} \mathrm{~cm}^{-1}$ Controls without enzyme were included with each assay to adjust for non-enzymatic hydrolysis of $p$ NPP. One unit of enzyme activity is defined as the amount of enzyme that is required to hydrolyze $1 \mu \mathrm{mol}$ of $p$ NPP per min at $37^{\circ} \mathrm{C}$. The TAP, TRAP and TALP activities were expressed as specific activity (U/ mg of total protein).

LDH, AST and ALT enzymes were assessed using Labtest kits (Labtest S.A., MG, Brazil). AST activity was measured by the method based on transfer of an amino group from L-aspartate to 2- $\alpha$-ketoglutarate with formation of oxaloacetate and L-glutamate and afterwards oxaloacetate was reduced to malate by malate dehydrogenase with simultaneous oxidation of NADH to NAD ${ }^{+}$. ALT activity, similar to AST, was analyzed by the method based on transfer of an amino group from L-alanine to 2- $\alpha$-ketoglutarate with formation of pyruvate, which was afterwards reduced to L-lactate by LDH with simultaneous oxidation of NADH to NAD ${ }^{+}$(Henry, Chiamori, Golub, \& Berkman, 1960; Karmen, 1955). In both cases, the reduction in absorbance at $340 \mathrm{~nm}$, resulting from NADH oxidation, was proportional to the ALT and AST activity in the sample. LDH activity in the supernatant was determined enzymatically, catalyzed in the interconversion of pyruvate and lactate in the presence of NADH. The reduction in absorbance at $340 \mathrm{~nm}$, resulting from NADH oxidation was proportional to the LDH activity in the sample (Huijgen, Sanders, Koster, Vreeken, \& Bossuyt, 1997). The activity values of LDH, ALT and AST were expressed as specific activity (U/mg of total protein).

\subsection{Statistical methods}

All biochemical parameters were analyzed in duplicate, at least. Data were analyzed for normality by using the Kolmogorov-Smirnov test. Data were expressed as mean \pm standard error of the mean. The influence of storage time was analyzed by one-way ANOVA followed by the Dunnett post-test, while the paired Student's- $t$ test was used to compare the differences between the temperatures on the same day. For all analyses, $p<0.05$ was considered statistically significant. Statistical analyses performed with GraphPad Prism 6 software (GraphPad Software, Inc.; La Jolla, CA, USA).

\section{Results}

No significant difference were observed in the salivary flow, $\mathrm{pH}$ or buffering capacity values, even when considering donor genders (Table 1).

Fig. 1 shows the salivary total protein concentrations at each time point and storage temperature tested. We observed no statistically significant changes in total salivary protein concentration over the storage periods in the samples stored at both temperatures.

Table 1

Mean \pm standard error of the mean values for age, flow rate, $\mathrm{pH}$, and volume of acid $0.01 \mathrm{~N} \mathrm{HCl}$ used in $\mathrm{pH}$ ranges of whole saliva from participants according to gender.

\begin{tabular}{lllll}
\hline Variables & & Man $(\mathrm{n}=14)$ & Woman $(\mathrm{n}=12)$ & $p$ value \\
\hline Flow rate (ml/min) & & $0.78 \pm 0.09$ & $0.61 \pm 0.08$ & $0.23^{\mathrm{a}}$ \\
$\mathrm{pH}$ & & $7.03 \pm 0.07$ & $6.9 \pm 0.08$ & $0.28^{\mathrm{a}}$ \\
Buffer capacity (ml & pHi-7.00 & $0.14 \pm 0.05$ & $0.10 \pm 0.04$ & $0.75^{\mathrm{b}}$ \\
$\quad$ acid/ml saliva) & pH 6.9-6.0 & $0.58 \pm 0.08$ & $0.47 \pm 0.05$ & $0.30^{\mathrm{b}}$ \\
& pH 5.9-5.0 & $0.36 \pm 0.03$ & $0.28 \pm 0.05$ & $0.15^{\mathrm{b}}$ \\
& pH 4.9-4.0 & $0.23 \pm 0.06$ & $0.23 \pm 0.05$ & $0.80^{\mathrm{b}}$ \\
\hline
\end{tabular}

\footnotetext{
p $<0.05$.

a The data were compared by Student's- $t$ test.

b The data were compared by Mann-Whitey tests.
}

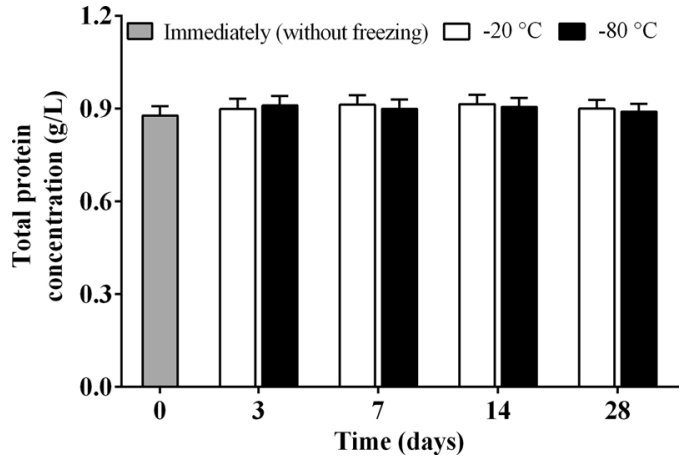

Fig. 1. Salivary total protein concentration of 26 subjects assayed immediately after centrifugation (without freezing) [baseline values] and after time intervals of 3, 7, 14 and 28 days of storage at $-20{ }^{\circ} \mathrm{C}$ and $-80^{\circ} \mathrm{C}$. Data represent the mean \pm standard error of the mean. The influence of storage time was analyzed by one-way ANOVA followed by Dunnett post-test ( ${ }^{*} p<0.05$ versus 0 day), while the paired $t$-test was used to compare the differences between the temperature in the same day (\#p<0.05 versus $-20^{\circ} \mathrm{C}$ ). Probability levels $<0.05$ were considered significant.

Total decline in enzymatic enzyme values after 28 days at $-20{ }^{\circ} \mathrm{C}$ and $-80^{\circ} \mathrm{C}$ are presented in Figs. 2 and 3. The activities of all enzymes in supernatant decreased significantly over 28 consecutive days after storage at $-20{ }^{\circ} \mathrm{C}$. This decrease began at least from day 7 onward for ALT, and day 14 onward for ACP, TRAP, ALP and ALT $(p<0.05)$, while the AST activity was significantly lower than baseline only at 28 day $(p<0.05)$. In turn, LDH was the most sensitive enzyme tested, since a marked reduction in its activity was already observed as from the 3rd day of storage at $-20^{\circ} \mathrm{C}$, compared with the baseline value. At the end of 28 days the samples stored at $-20{ }^{\circ} \mathrm{C}$ showed a reduction of $36 \%$ (ACP), 49\% (TRAP), 60\% (ALP), 38\% (ALT), 32\% (AST) and $84 \%$ (LDH) in enzymatic activity values.

There were considerable, but insignificant changes, in the activity values of all enzymes after 28 day of storage at $-80{ }^{\circ} \mathrm{C}$. Under these conditions, there was a decrease of 16\% (ACP), 17\% (TRAP), $28 \%$ (ALP), $16 \%$ (ALT), $4 \%$ (AST) and 18\% (LDH) in enzymatic activity values.

If we consider the acceptable maximum variation threshold at $10 \%$ of enzymatic activity, none of the enzymes analyzed could be stored at $-20{ }^{\circ} \mathrm{C}$. Storage at $-80^{\circ} \mathrm{C}$ kept the samples viable for enzymatic analysis of ALP, ALT and LDH for up to 3 days; ACP and TRAP for 10 days, while the maximum variation of AST activity was less than $10 \%$ after 28 days of storage.

For the majority of enzymes, with the exception of AST, the differences between the temperatures on the same day of each time point of analysis were statistically significant as from the 3rd day of storage.

\section{Discussion}

Saliva collection and analysis is becoming increasingly routine in both clinical dentistry and basic scientific research. A wide range of biomarkers of systemic and oral diseases are measurable in saliva, including heavy metals; hormones; toxins and their metabolites; enzymes; immunoglobulins; other proteins and DNA. The stability of these biomarkers during storage is a methodological topic that needs to be considered, particularly when the setting places restrictions on how samples can be processed and stored after collection, especially in relation to access to freezers $-80^{\circ} \mathrm{C}$. Furthermore, some situations require the storage of saliva samples at low temperatures for very long periods of time, for example, saliva bank samples and longitudinal studies involving the prospection of clinical practices and treatments. Therefore, the main purpose of the present study was to investigate the influence of storage temperature at $-20{ }^{\circ} \mathrm{C}$ compared with $-80{ }^{\circ} \mathrm{C}$ on salivary ACP, TRAP, ALP, ALT, AST and LDH activity values, immediately and after time intervals of $3,7,14$ and 28 days of storage. 

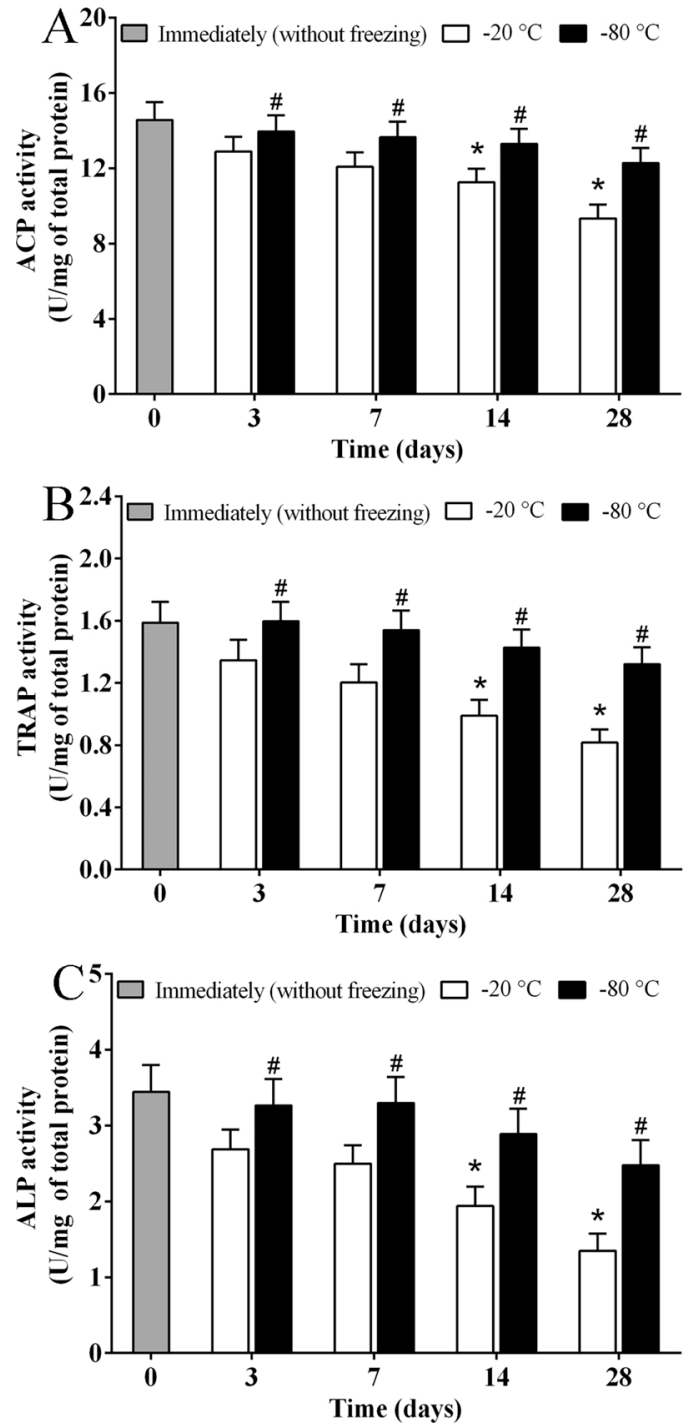

Fig. 2. Salivary ACP (A), TRAP (B) e ALP (C) activities of 26 subjects assayed immediately after centrifugation (without freezing) [baseline values] and after time intervals of 3, 7, 14 and 28 days of storage at $-20^{\circ} \mathrm{C}$ and $-80^{\circ} \mathrm{C}$. Data represent the mean \pm standard error of the mean. The influence of storage time was analyzed by one-way ANOVA followed by Dunnett post-test ( $* p<0.05$ versus 0 day), while the paired $t$-test was used to compare the differences between the temperature in the same day $\# p<0.05$ versus $-20{ }^{\circ} \mathrm{C}$ ). Probability levels $<0.05$ were considered significant.

Although protein stability of saliva samples has been reported when stored on ice at $-20{ }^{\circ} \mathrm{C}$ and at $-80{ }^{\circ} \mathrm{C}$ (Schipper, Loof et al., 2007), this is the first study to report on the stability of salivary ACP, TRAP, ALP, ALT and AST activity values in freezer conditions and over time. Our results made it evident that the enzyme values were more stable in samples stored in a $-80{ }^{\circ} \mathrm{C}$ freezer compared with $-20{ }^{\circ} \mathrm{C}$ conditions. Variation in all enzyme activity values were higher than $30 \%$ for samples stored at $-20{ }^{\circ} \mathrm{C}$ for up 28 days compared with baseline values, while in the same period at $-80^{\circ} \mathrm{C}$, the variation in activity values was approximately $15 \%$ for the majority of enzymes, except AST.

Contrary to our results, other salivary proteins such as salivary IgA and lysozyme concentrations remained stable for up to 3 months when stored at $-30{ }^{\circ} \mathrm{C}$ ( $\mathrm{Ng}$ et al., 2003), while salivary alpha-amylase was stable after 5 days at room temperature, and freeze-thaw cycles at $-20{ }^{\circ} \mathrm{C}$ (O’Donnell, Kammerer, O’Reilly, Taylor, \& Glover, 2009). Similar to our results, studies have demonstrated a significant degradation of the LDH activity in saliva supernatant samples, as from $24 \mathrm{~h}$ of storage at $-20{ }^{\circ} \mathrm{C}$ (De La Peña, Diz Dios, \& Tojo Sierra, 2007). In this same study, the recommendation was to store the samples at $4{ }^{\circ} \mathrm{C}$.
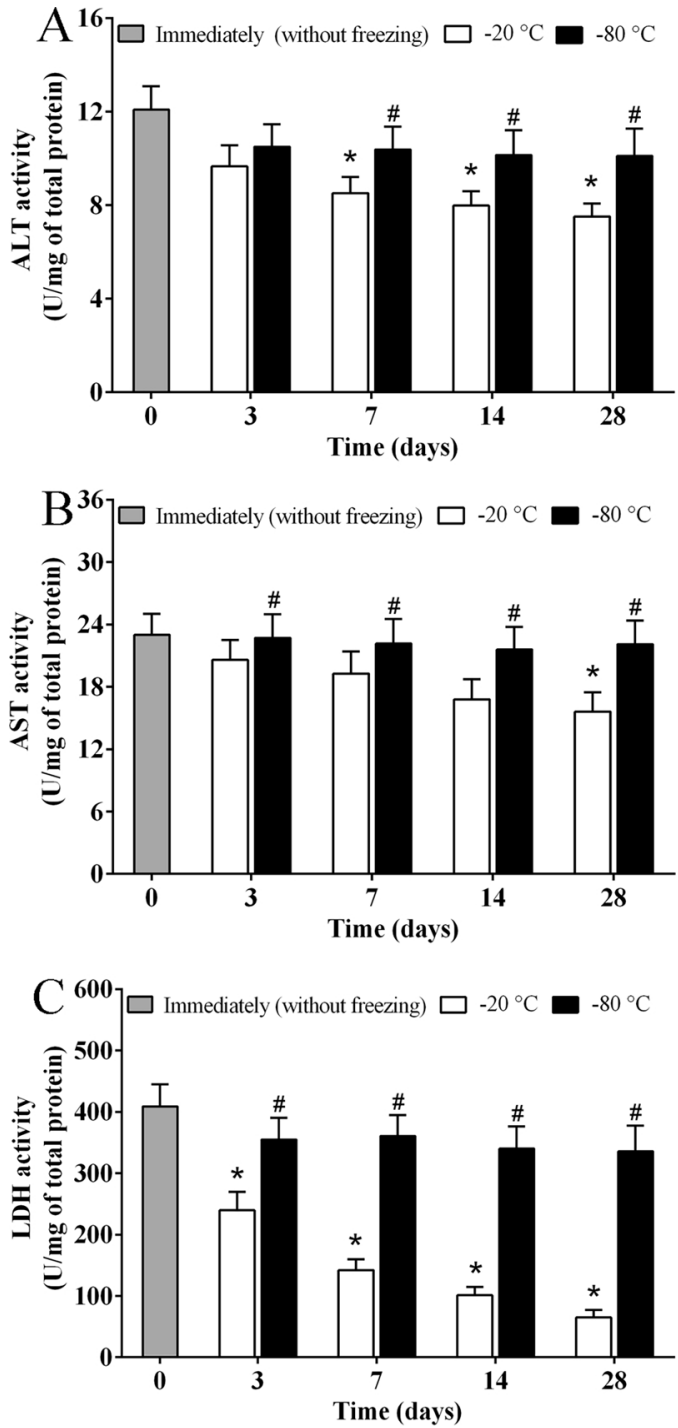

Fig. 3. Salivary ALT (A), AST (B) e LDH (C) activities of 26 subjects assayed immediately after centrifugation (without freezing) [baseline values] and after time intervals of 3,7 , 14 and 28 days of storage at $-20^{\circ} \mathrm{C}$ and $-80^{\circ} \mathrm{C}$. Data represent the mean \pm standard error of the mean. The influence of storage time was analyzed by one-way ANOVA followed by Dunnett post-test ( ${ }^{*} p<0.05$ versus 0 day), while the paired $t$-test was used to compare the differences between the temperature in the same day $\# p<0.05$ versus $-20^{\circ} \mathrm{C}$ ). Probability levels $<0.05$ were considered significant.

There is still some concern in the literature regarding the stability of these enzymes in the body fluids. Some of these studies were in agreement with our data. For example, marked ALT serum loss occurred with storage at $-20{ }^{\circ} \mathrm{C}$, whereas storage at $-80^{\circ} \mathrm{C}$ resulted in a lower decrease (Jansen, Beekhof, Viezeliene, Muzakova, \& Skalicky, 2015; Williams, Williams, Kline, \& Dodd, 1987). ACP underwent a more or less rapid loss of activity when human cerebrospinal fluid was stored for 15 days in the temperature range from $37^{\circ} \mathrm{C}$ to $-80^{\circ} \mathrm{C}$, while storage in liquid nitrogen $\left(-196^{\circ} \mathrm{C}\right)$ was the only condition in which full ACP activity was maintained for at least 15 days (Goi et al., 1987). In contrast to our findings, Kachhawa et al. (Kachhawa et al., 2017) showed adequate stability of AST, ALT and ALP in serum after 30 days of storage at $-20{ }^{\circ} \mathrm{C}$; whereas (Jung, Bader, \& Grützmann (1984) showed evidence that ALT, AST, LDH and ALP serum presented a long time of stability only when stored in liquid nitrogen.

The mechanisms related to the loss of the enzymatic activity of the samples was beyond the scope of this study, and cannot be explained by the methodology that was used, but possible explanations include changes in sample $\mathrm{pH}$, bacterial multiplication, freezing denaturation 
and extensive proteolytic cleavage by endogenous and exogenous proteases. Presser et al. (2014) also considered it important to note that the high viscosity of saliva samples made it difficult to pipette the samples precisely, even after vortexing undiluted expectorated samples, so human error cannot be ruled out.

The present data must be interpreted considering the following methodological limitations: firstly, that the power to detect minor differences in a study sample of 24 was limited. Secondly, we worked with saliva collected by expectoration followed by centrifugation. Thirdly, saliva samples were obtained only from healthy volunteers. Future researchers could consider whether the results obtained in the present study remain when using another collection method; native saliva; chemical additives to avoid protein freeze damage; protease enzyme inhibitors, and/or saliva samples obtained from patients with gingivitis, periodontitis or oral cancer.

From interpretation of experimental results, it was possible to confirm our hypothesis that temperature and storage time may affect the saliva of healthy individuals. Frozen samples should be kept at $-80^{\circ} \mathrm{C}$ to preserve the enzymatic activities, but there are restrictions for the enzymes ALP, ALT and LDH. For measurement of ACP, TRAP, ALP, AST, ALT and LDH, storage of sample at $-20{ }^{\circ} \mathrm{C}$ could introduce large error variance in measured activities. In the absence of a freezer $-80^{\circ} \mathrm{C}$, it is strongly recommended that the samples be processed and analyzed immediately after collection.

\section{Conflict of interest}

The author(s) declare no potential conflicts of interest with respect to the authorship and/or publication of this article.

\section{Funding}

The project was developed without funding.

\section{Ethical Approval}

The research protocol was approved by the Human Ethics Committee on Research with Human Beings of the School of Dentistry, Araçatuba, São Paulo State University - UNESP (Permission Number CAAE 44627915.0.0000.5420 and 50712215.3.0000.5420).

\section{Acknowledgments}

We thank the participants for their cooperation. The scientific initiation projects were approved by São Paulo State University - UNESP (Number of the Projects 36151 and 33749).

\section{References}

Al Kawas, S., Rahim, Z. H., \& Ferguson, D. B. (2012). Potential uses of human salivary protein and peptide analysis in the diagnosis of disease. Archives of Oral Biology, 57(1), 1-9.

Alptekin, N. O., Kurtoglu, F., Serpek, B., Duran, I., \& Gözlü, M. (2000). Effects on the clinical indices and gingival crevicular fluid enzyme activities of the cyclical regimen of low-dose doxycycline therapy for adult periodontitis. Journal of the International Academy of Periodontology, 2(1), 3-8.

Bassoukou, I. H., Nicolau, J., \& dos Santos, M. T. (2009). Saliva flow rate, buffer capacity, and $\mathrm{pH}$ of autistic individuals. Clinical Oral Investigations, 13(1), 23-27.

Boghori, M., Aghamaali, M., Sariri, R., Mohamadpour, F., \& Ghafouri, H. (2014). Salivary enzymes and flow rate: Markers of peptic ulcer. Journal of Oral Biology and Craniofacial Research, 4(1), 24-29.

Cesco, R. T., Ito, I. Y., \& de Albuquerque, R. F. (2003). Levels of aspartate aminotransferase (AST) in saliva of patients with different periodontal conditions. Journal of Clinical Periodontology, 30(8), 752-755.

Chaves-Neto, A. H., Sassaki, K. T., \& Nakmune, C. M. S. (2011). Protein phosphatase activities in the serum and saliva of healthy children RPG. Revista da Pós-Graduação, 18(2), 90-95.

Dabra, S., \& Singh, P. (2012). Evaluating the levels of salivary alkaline and acid phosphatase activities as biochemical markers for periodontal disease: A case series. Dental Research Journal (Isfahan), 9(1), 41-45.

Dabra, S., China, K., \& Kaushik, A. (2012). Salivary enzymes as diagnostic markers for detection of gingival/periodontal disease and their correlation with the severity of the disease. Journal of Indian Society of Periodontology, 16(3), 358-364.

De La Peña, V. A., Diz Dios, P., \& Tojo Sierra, R. (2007). Relationship between lactate dehydrogenase activity in saliva and oral health status. Archives of Oral Biology, 52(10), 911-915.

Emekli-Alturfan, E., Yarat, A., Çalışkan-Ak, E., Pisiriciler, R., Kuru, B., \& Noyan, Ü. (2013). Determination of storage time of saliva samples obtained from patients with and without chronic periodontitis for the comparison of some biochemical and cytological parameters. Journal of Clinical Laboratory Analysis, 27(4), 261-266.

Fiorellini, J. P., Nevins, M. L., Sekler, J., Chung, A., \& Oringer, R. J. (2000). Correlation of peri-implant health and aspartate aminotransferase levels: a cross-sectional clinical study. International Journal of Oral and Maxillofacial Implants, 15(4), 500-504.

Flink, H., Tegelberg, A., \& Lagerlöf, F. (2005). Influence of the time of measurement of unstimulated human whole saliva on the diagnosis of hyposalivation. Archives of Oral Biology, 50(6), 553-559.

Garde, A. H., \& Hansen, A. M. (2005). Long-term stability of salivary cortisol. Scandinavian Journal of Clinical and Laboratory Investigation, 65(5), 433-436.

Goi, G., Fabi, A., Lombardo, A., Burlina, A. B., Tiby, V., Visciani, A., et al. (1987). Stability of enzymes of lysosomal origin in human cerebrospinal fluid. Clinica Chimica Acta, 163(2), 215-224.

Granjeiro, J. M., Taga, E. M., \& Aoyama, H. (1997). Purification and characterization of a low-molecular-weight bovine kidney acid phosphatase. Anais da Academia Brasileira de Ciencias, 69(4), 451-460.

Hartree, E. F. (1972). Determination of protein: A modification of the Lowry method that gives a linear photometric response. Analytical Biochemistry, 48(2), 422-427.

Henry, R. J., Chiamori, N., Golub, O. J., \& Berkman, S. (1960). Revised spectrophotometric methods for the determination of glutamic-oxalacetic transaminase, glutamic-pyruvic transaminase, and lactic acid dehydrogenase. American Journal of Clinical Pathology, 34, 381-398.

Henson, B. S., \& Wong, D. T. (2010). Collection, storage: And processing of saliva samples for downstream molecular applications. Methods in Molecular Biology, 666, 21-30.

Huijgen, H. J., Sanders, G. T., Koster, R. W., Vreeken, J., \& Bossuyt, P. M. (1997). The clinical value of lactate dehydrogenase in serum: A quantitative review. European Journal of Clinical Chemistry and Clinical Biochemistry, 35(8), 569-579.

Janckila, A. J., Parthasarathy, R. N., Parthasarathy, L. K., Seelan, R. S., Hsueh, Y. C., Rissanen, J., et al. (2005). Properties and expression of human tartrate-resistant acid phosphatase isoform 5a by monocyte-derived cells. Journal of Leukocyte Biology, $77(2), 209-218$.

Jansen, E., Beekhof, P., Viezeliene, D., Muzakova, V., \& Skalicky, J. (2015). Long-term stability of cancer biomarkers in human serum: Biomarkers of oxidative stress and redox status, homocysteine, CRP and the enzymes ALT and GGT. Biomarkers in Medicine, 9(5), 425-432.

Jung, K., Bader, K., \& Grützmann, K. D. (1984). Long-term stability of enzymes in human serum stored in liquid nitrogen. Enzyme, 31(4), 209-216.

Kachhawa, K., Kachhawa, P., Varma, M., Behera, R., Agrawal, D., \& Kumar, S. (2017) Study of the stability of various biochemical analytes in samples stored at different predefined storage conditions at an accredited laboratory of India. Journal of Laboratory Physicians, 9(1), 11-15.

Karmen, A. (1955). A note on the spectrometric assay of glutamic-oxalacetic transaminase in human blood serum. The Journal of Clinical Investigation, 34(1), 131-133.

Kaufman, E., \& Lamster, I. B. (2000). Analysis of saliva for periodontal diagnosis-A review. Journal of Clinical Periodontology, 27(7), 453-465.

Kaufmann, G., Dautzenberg, H., Henkel, H., Müller, G., Schäfer, T., Undeutsch, B., et al . (1999). Nitrile hydratase from Rhodococcus erythropolis: Metabolization of steroidal compounds with a nitrile group. Steroids, 64(8), 535-540.

Kugahara, T., Shosenji, Y., \& Ohashi, K. (2008). Screening for periodontitis in pregnant women with salivary enzymes. Journal of Obstetrics and Gynaecology Research, 34(1), 40-46.

López, M. E., Colloca, M. E., Páez, R. G., Schallmach, J. N., Koss, M. A., \& Chervonagura, A. (2003). Salivary characteristics of diabetic children. Brazilian Dental Journal, 14(1), 26-31.

Laidler, P. M., Taga, E. M., \& Van Etten, R. L. (1982). Human liver acid phosphatases: Cysteine residues of the low-molecular-weight enzyme. Archives of Biochemistry and Biophysics, 216(2), 512-521.

Malicka, B., Skoskiewicz-Malinowska, K., \& Kaczmarek, U. (2016). Salivary lactate dehydrogenase and aminotransferases in diabetic patients. Medicine, 95(47), e5211.

Musumeci, V., Cherubini, P., Zuppi, C., Zappacosta, B., Ghirlanda, G., \& Di Salvo, S. (1993). Aminotransferases and lactate dehydrogenase in saliva of diabetic patients. Journal of Oral Pathology and Medicine, 22(2), 73-76.

Nagler, R. M., Hershkovich, O., Lischinsky, S., Diamond, E., \& Reznick, A. Z. (2002). Saliva analysis in the clinical setting: Revisiting an underused diagnostic tool. Journal of Investigative Medicine, 50(3), 214-225.

Naumova, E. A., Sandulescu, T., Bochnig, C., Gaengler, P., Zimmer, S., \& Arnold, W. H. (2012). Kinetics of fluoride bioavailability in supernatant saliva and salivary sediment. Archives of Oral Biology, 57(7), 870-876.

Navazesh, M. (1993). Methods for collecting saliva. Annals of the New York Academy of Sciences, 694, 72-77.

Ng, V., Koh, D., Fu, Q., \& Chia, S. E. (2003). Effects of storage time on stability of salivary immunoglobulin A and lysozyme. Clinica Chimica Acta, 338(1-2), 131-134.

O’Donnell, K., Kammerer, M., O'Reilly, R., Taylor, A., \& Glover, V. (2009). Salivary alphaamylase stability, diurnal profile and lack of response to the cold hand test in young women. Stress, 12(6), 549-554.

Oglesbee, L. H., Seale, T. W., Mayes, J. S., Flux, M., Young, S. K., \& Renner, O. M. (1984). Plasma and submandibular saliva lysosomal enzymes in cystic fibrosis. Clinica Chimica Acta, 143(2), 135-145.

Pannunzio, E., Amancio, O. M., Vitalle, M. S., Souza, D. N., Mendes, F. M., \& Nicolau, J. 
(2010). Analysis of the stimulated whole saliva in overweight and obese school children. Revista Da Associacao Medica Brasileira (1992), 56(1), 32-36.

Prakash, A. R., Indupuru, K., Sreenath, G., Kanth, M. R., Reddy, A. V., \& Indira, Y. (2016). Salivary alkaline phosphatase levels speak about association of smoking, diabetes and potentially malignant diseases??? International Journal of Oral and Maxillofacial Pathology, 20(1), 66-70.

Presser, E., Simuyandi, M., \& Brown, J. (2014). The effects of storage time and temperature on recovery of salivary secretory immunoglobulin A. American Journal of Human Biology, 26(3), 417-420.

Schipper, R., Loof, A., de Groot, J., Harthoorn, L., Dransfield, E., \& van Heerde, W. (2007). SELDI-TOF-MS of saliva: Methodology and pre-treatment effects. Journal of Chromatography B, Analytical Technologies in the Biomedical and Life Sciences, 847(1), 45-53.

Schipper, R. G., Silletti, E. \& Vingerhoeds, M. H. (2007). Saliva as research material: Biochemical, physicochemical and practical aspects. Archives of Oral Biology, 52(12), 1114-1135.

Sophia, K., Suresh, S., Sudhakar, U., Jayakumar, P., \& Mathew, D. (2017). Comparative analysis of salivary alkaline phosphatase in post menopausal women with and without periodontitis. Journal of Clinical and Diagnostic Research, 11(1), ZC122-ZC124.

Toone, R. J., Peacock, O. J., Smith, A. A., Thompson, D., Drawer, S., Cook, C., et al (2013). Measurement of steroid hormones in saliva: Effects of sample storage condition. Scandinavian Journal of Clinical and Laboratory Investigation, 73(8), 615-621.

Totan, A., Greabu, M., Totan, C., \& Spinu, T. (2006). Salivary aspartate aminotransferase, alanine aminotransferase and alkaline phosphatase: Possible markers in periodontal diseases? Clinical Chemistry and Laboratory Medicine, 44(5), 612-615.

Verma, M., Metgud, R., Madhusudan, A. S., Verma, N., Saxena, M., \& Soni, A. (2014). A comparative study of glutamate oxaloacetate transaminase (GOT) and glutamate pyruvate transaminase (GPT) levels in the saliva of diabetic and normal patients. Biotechnic and Histochemistry, 89(7), 529-534.

Williams, K. M., Williams, A. E., Kline, L. M., \& Dodd, R. Y. (1987). Stability of serum alanine aminotransferase activity. Transfusion, 27(5), 431-433.

Yoshie, H., Tai, H., Kobayashi, T., Oda-Gou, E., Nomura, Y., Numabe, Y., et al. (2007). Salivary enzyme levels after scaling and interleukin-1 genotypes in Japanese patients with chronic periodontitis. Journal of Periodontology, 78(3), 498-503. 